\title{
MANAGEMENT OF MOISTURE RESOURCE POTENTIAL IN AGROCENOSES OF FOREST-STEPPE OF UKRAINE
}

\author{
Olexander Demidenko ${ }^{1 *}$, Petro Boiko ${ }^{2}$, Yaroslav Tsimbal ${ }^{2}$, Nataliia Kovalenko ${ }^{3}$ \\ ${ }^{1 *}$ Cherkassy State Agricultural Scientific Research Station of NSC "Institute of Agriculture NAAS", Ukraine; \\ ${ }^{2} N S C$ "Institute of Agriculture NAAS”, Ukraine; \\ ${ }^{3}$ Institute of History of Agrarian Science, Education and Technique of NSAL of NAAS, Ukraine; \\ *Corresponding Author Olexander Demidenko, e-mail: smilachiapv@ukr.net; agrogumys@ukr.net;
}

Received September 2020; Accepted October 2020; Published November 2020;

DOI: https://doi.org/10.31407/ijees10.423

\begin{abstract}
To define the factors of managing the potential of moisture resources, the regularities of accumulation and use of moisture from soil by agricultural crops while cultivating them in the system of different crop rotations in the Forest-Steppe of Ukraine. The comparative assessment of the productivity of cereal-hoed 10-field rotation demonstrated that in 2010-2015 the yield of dry substance of the main product increased 1.35 times, the yield of fodder units -1.28 times, and that of cereals -1.23 times. The fraction of the yield of dry substance was $12 \%$ from the total yield which was 2.3 times higher as compared to 1965-1969. The introduction of mineral fertilizers in 5field cereal-hoed rotation promoted the increase in the yield of fodder units by $35.7 \%$, cereal units - by $29.1 \%$. The highest yield from the fertilizers introduced was obtained for tillage, where the yield of fodder and cereal units increased by 56.6 and $60.7 \%$ respectively. Short crop rotations had higher productivity: strong direct correlation $(\mathrm{R}>0.70)$ was found between the accumulation of energy in dry substance and the yield of dry substance, fodder and cereal units and the accumulation of energy per $10 \mathrm{t}$ of the moisture used. Regression coefficients for the variables: dry substance, fodder and cereal units, dry substance per $10 \mathrm{t}$ of moisture in the dependence equations were 3.06, $1.25,7.25$ and 2.89 times higher as compared to long crop rotations. It demonstrated the 2.59 -fold higher efficiency of forming productivity in short crop rotations and using the total moisture circulation as compared to long crop rotations.
\end{abstract}

Keywords: crop rotations of different duration, predecessors, rotation norms, moisture provision, soil properties, evaporation, agrotechnical measures, cultivation culture. 